\title{
Collective Impact Approach: A “Tool” for Managing Complex Problems and Business Clusters Sustainability
}

\author{
Alessandra De Chiara
}

\begin{abstract}
Environmental pollution occurring in industrial districts represents a serious issue not only for local communities but also for those industrial productions that draw from the territory the source of their competitiveness. Due to its ability to take into account the needs of different stakeholders, the collective impact approach has the potential to address these problems, whereas single actors may not have the resources. The implications of the paper are addressed to institutions for industrial policies which individuate potential courses of action for developing and strengthening clustering-based approaches, as well as implementing viable policies in support of the sustainable competitive model.
\end{abstract}

Keywords: Collective impact; sustainability; industrial districts; social welfare; multistakeholders

\section{Sustainability and the Collective Impact Approach: The Importance of Relationships}

Facing environmental problems and implementing sustainability plans requires a relational approach for obtaining concrete results. Relational approaches are quite clear in their different theoretical guidelines related to sustainability: at the firm level (i.e., corporate social responsibility [CSR]), the relational approach explains its implementation process and refers to obtainable benefits at organizational, customer, and society-based level (trust, reputation, motivation, commitment, transparency, etc.) (Orlitzky et al., 2003; Porter and Kramer, 2006; Perrini et al., 2006); at the production-line level, it refers to the management of relationships within the supply chain (Carter \& Jennings, 2002; Reuter et al., 2010); at the network and system level it refers to the positive impact on the entire community (Hemmati, 2002; Zadek, 2006; Caroli \& Tantalo, 2011).

Collaboration with institutions, communities, and businesses is crucial, especially at a time of limited economic resources, private and public alike. Therefore, the creation of networks and the development of new synergies are the key premises to improve efficacy and efficiency of operations. The collaboration with different stakeholders contributes to accessing innovative potential that exists within the cooperation (Tencati \& Zsolnai, 2009), and increases the value and quality of processes and outputs (Dallocchio et al., 2010). Collaboration also allows the participation of small and medium-sized businesses (SMEs) (Speence \& Schmidpeter, 2003). For these actors, relationships and stakeholder engagement are vital connectors and amongst the best viable approaches for sustainability development. SMEs should engage in responsible conduct due to their strong ties to the local system (Harvey et al., 1991; Perrini \& Tencati, 2008), while the ability to develop harmonic and trustful relationships with stakeholders remains the basis of their long-term performance (Spence et al., 2003). 
Above all, the engagement of various stakeholders assures an increased level of sustainability within the entire supply chain or local system, with a positive impact on the whole community, while preventing the unethical misconduct of others from undermining the efforts. Stakeholder engagement plays a crucial role in two respects. In the decision-making process, it allows for the inclusion of different variables and needs and the choice of sustainable initiatives and polices to satisfy the expectations of all parties involved. Furthermore, in the processes of implementing decisions and strategies, engagement provides a powerful means to ensure a positive spin-off for sustainable development. This relational approach allows for the creation of common visions and missions, reduced environmental impact, and an application of rules within each organization, providing higher standards for working conditions (Fichter \& Sydow, 2002).

While it is true that the multi-stakeholder approach has become the indispensable pillar of sustainability strategies within supply chains, networks, and local systems, very often collaborative interactions are not sufficient. For example, in the presence of complex problems, engagement often fails (Kania and Kramer, 2011). In the collective impact approach, it is argued that engagement should evolve from an informal to a more collaborative-based approach with a well-defined organizational structure. Managing change in terms of complex problems, such as pollution or social unease, has prompted this approach to define projects based on a regulated engagement, so as to effectively contribute to the well-being of the community (Hanleybrown et al., 2012; Kania \& Kramer, 2011). This approach underlines that "large-scale social change requires a broad cross-sector coordination" and a commitment by "a group of important actors from different sectors to a common agenda to solve a specific social problem” (Kania \& Kramer, 2011, p. 36). This perspective stresses that the different types of traditional collaborations, such as the funder collaborative, public-private partnerships, multi-stakeholder initiatives, and social sector networks organizations, have failed in the attempt to solve complex social problems. The collective impact approach refers to a type of collaboration that solicits a separate organization (or organizations) with specific sets of staff skills, shared tools, and a structured process to create a common agenda.

This perspective identifies the need to create a backbone structure with a dedicated staff to cope with complex issues or adaptive problems, i.e., the education reform, rehabilitation of polluted sites, improvement and protection of health of the community, etc., and other factors preventing single enterprises from enabling change.

Establishing a centralized structure should prompt the involved parties to implement a common agenda through a structured process that identifies the sub-objectives and strategies, shared tools, communications means, and measuring results systems (Kania \& Kramer, 2011). The model suggested by the collective impact approach starts with the identification of some pre-conditions to establish the required contributions and work phases, which are divided into three major stages (Figure 1). The first stage focuses on defining the initial preparation related to the group composition, history of the territory or community, and database collection. The second stage refers to the definition of a backbone structure, the creation of a common agenda with specific objectives and strategies, promotion of the community engagement, and implementation of measuring procedures. The third stage deals with the pursuit of actions for the implementation of objectives and strategies, community engagement monitoring, and effective feedback processes. 


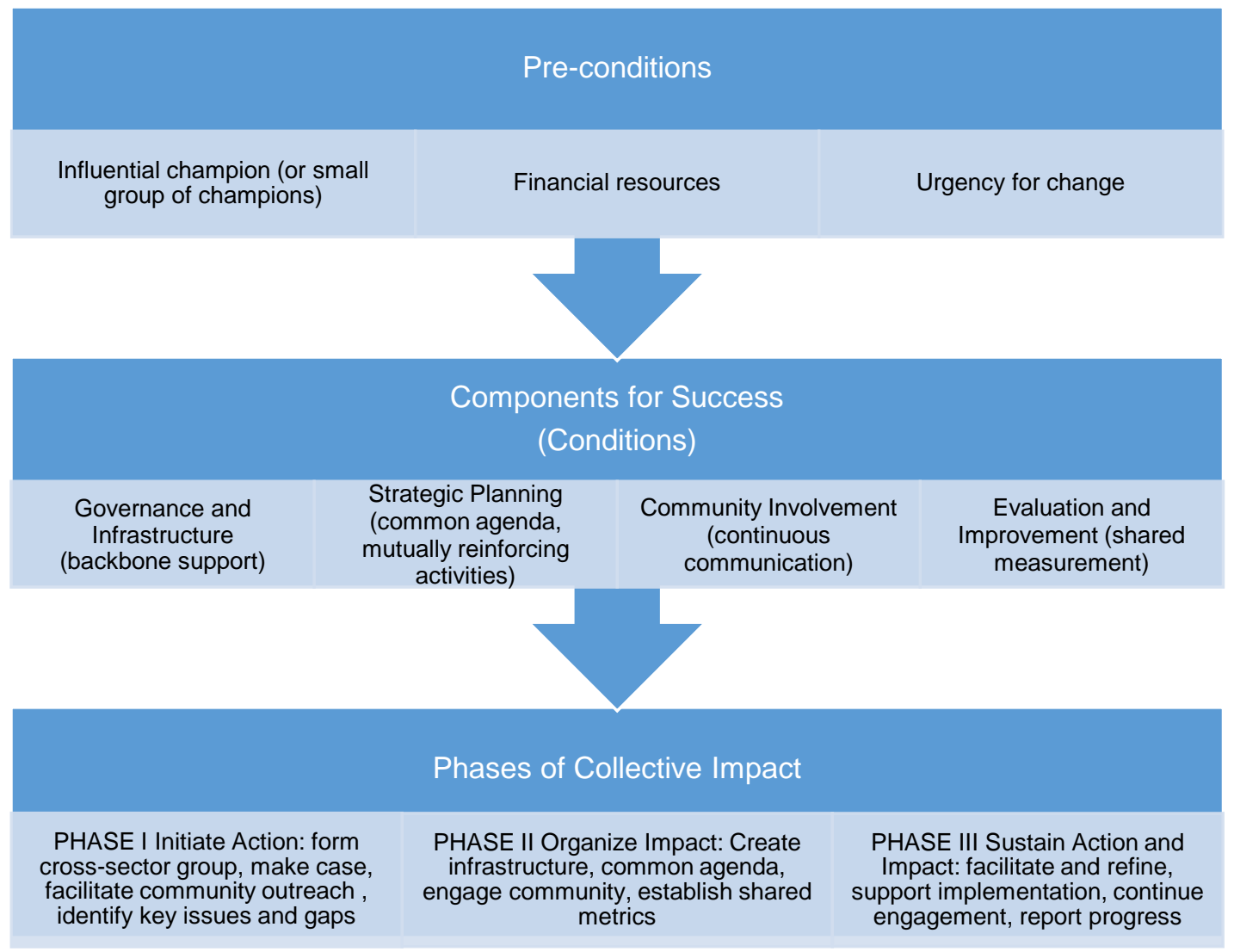

Figure 1. Pre-conditions, components, and phases for the implementation of the collective impact approach (adapted from Hanleybrown et al. 2012)

Members' behavior is fundamental in the collective impact approach. Kania and Kramer (2011, p. 39) state that the success of this approach "is not merely a matter of encouraging more collaboration or public-private partnerships. It requires a systemic approach to social impact that focuses on the relationships between organizations and the progress toward shared objectives." They add that the "expectation that collaboration can occur without a supporting infrastructure is one of the most frequent reasons why it fails” (Kania \& Kramer, p. 41).

\section{Collective Impact Approach for Sustainability in Business Clusters}

Sustainability is also an opportunity to build collaborative interactions and partnerships between public and private actors, which can enhance competitiveness of a local system. Establishing a special bond among economic, institutional, and social systems appears an essential precondition not only to manage an area with a complex problem of pollution, but also for enhancing its territorial specialization and distinctiveness.

The identification of sustainable paths, capable of re-qualifying local processes and products and of boosting local economy and improving its competitive advantage, can be investigated by way of the collective impact approach. This perspective is applicable to those areas where economicproductive tissue has the characteristics of a milieu, that is to say, a high concentration of 
production systems which has strong ties to the socio-cultural features of a territory (Beccatini \& Sforzi, 2002). The set of natural conditions characterizes a given territory, and all permanent socio-cultural aspects rooted in a specific geographical area are due to the historical evolution of their inter-subjective connections and ties to local environmental ecosystems (Beccatini \& Sforzi, 2002). Actors, resources, activities, and relationships are thus the territory's core elements, which has led the territorial dimension to progressively emerge as a significant key of interpretation to how production is organized and implemented in different contexts.

The influence of the territory on business competitiveness has been widely investigated in the theoretical debate i.e., the classical economy, the theory of business clusters, the international marketing and territorial marketing researches. These theories have examined all salient aspects from different angles, and agreed on the undeniable value and power of the territory over business competitiveness.

In the idea of business cluster, there is an interconnection between economic production and socio-cultural conditions, which significantly contributes to business profitability. In current times, the renewed interest in clusters appears to have its grounds in its role as a development vector for local economies. In debate, the relationships between "businesses, external economies, and economic development” and technologies, spillovers, agglomerations, and regional economic development have been extensively investigated (Feser \& Bergman, 2000).

Business clusters are integral parts of the territorial heritage since they mirror the area in which they are embedded. At the same time, places reflect the specific characteristics of a productive business network, thus, the comparative advantage arising from the specific resources of the area in line with sustainable strategic approaches would not only foster district upgrading and businesses/local system competitiveness, but also strengthen the district interconnected relationships with its cultural background (Beccatini, 2000).

Where the territory is strongly influenced by the presence of an industrial district, and in turn the district is conditioned by the socio-cultural features of a territory, the collective impact approach could intervene in:

- defining a strategic plan with a common agenda for the implementation of sustainability projects created for the social and economic development of the area;

- determining the participation of economic, social, and political actors with the establishment of a backbone structure;

- $\quad$ promoting communication and measuring procedures.

The single parties have an important role but they need to join together to pursue a common project; for this aim the collective impact can be a useful approach.

Companies have the capacity to exploit the relational, social, and cultural fabric of their places of production. They can use their relationships and social capital to create a unique network abounding with cultural traditions and expertise in each different territory. However, within districts, the common geographic relationships must evolve toward a relation-based and shared management approach. Common social roots, competences, and knowledge sharing may 
reinforce social interactions, but this transition does not occur automatically when considering the overall competitive network of business clusters relationships. Clustering activities, when relying on a high level of productive business interdependence and relationships based on trust, turn out to be an asset for the implementation of sustainability plans aimed at improving district performances, local system well-being, and enterprise competitiveness. It is equally true, however, that significant governance concerns and considerable problems arise in the adoption of suitable tools to foster engagement.

Similarly, institutions have an equally important role of balancing the differences of all the actors so that the network constitutes an effective resource for local development: some authors note that "local solutions of civic-engagement and self-regulation are playing an increasing role in guaranteeing successful interaction in everyday-life” (Spence \& Schmidpeter, 2003, p. 96). The institutions aim to develop policies and services for companies and to value the networks and territory's aptitudes and inclinations (Iannone, 2007; Barile et al., 2013), as well as to create conditions so even small-sized companies can increase their contribution to the common good (Bennett, 1999). Public institutions need to play an active role in the civil society and trigger a learning process that will facilitate the adoption of sustainable behavioral patterns (Rivoli \& Waddock, 2011). Local authorities should find the right balance between legislation and appropriate actions to pursue. This enables districts and production centers to adopt sustainable competitive models, not only for their own benefit, but also for the well-being of the community as a whole. In this respect, the viable sustainable approach of local business clusters is crucial as it sets the scene for regular output and activity upgrading, which, in turn, will boost production competitiveness. Institutional governance standards of conduct should enhance local expertise as well as the distinctive features of every single process to create those unique competitive models capable of contributing to the social and economic development of the entire community.

Finally, research has emphasized the important role of the community in shaping business behaviors and calls upon local authorities to re-establish or enforce new regulations (Calvano, 2008). Therefore, the work of institutions must function alongside the work of the companies that are connecting with other economic actors and institutions to benefit from their social capital. For sustainable development of an area, it is necessary to consolidate relationships between companies and local systems, connecting the company and the local environment (Iannone, 2007; Pilotti et al., 2013). The collective impact approach can enhance engagement on a local level, pursuing economic competitiveness and social welfare. Both of these benefit from a relationship of mutual conditioning. It is not only necessary to create cross-sector public and private partnerships, but also to initiate a systematic approach focused on the relationships between different stakeholders and a progression toward shared goals.

\section{Some Experiences: The Failure of Traditional Networks}

This paper reports the experiences of two cases that describe the failure of traditional networks in the presence of a complex problem of pollution in areas where significant industrial districts are located.

The first case refers to the environmental crisis of an area in the south of Italy, called the "The Land of Fires," which has created serious difficulties for the structural stability of many agro- 
food businesses, and indeed, the entire community. To face this problem, businesses have promoted a network involving other economic actors of the area, as well as local public institutions. Despite many efforts over the years, this network has failed.

The second case refers to the experience of the tannery district of Solofra in the south of Italy which has planned a significant environmentally sustainable project, described as an eco-label scheme for the district of Solofra. Though there are many certified eco-labeled businesses in the district, the project is failing due to both a lack of funding and, above all, the lack of a welldefined and structured governance for planning and implementing the district's sustainable development.

These two cases highlight critical elements that led to the failure of the traditional networks, and collect the reflections of the actors involved and managerial problems of the engagement. It is believed these difficulties could diminish or even disappear if management of the cooperation is organized according to the approach of collective impact, especially after the setting of a backbone support and a common agenda.

\section{The Environmental Crisis of the "The Land of Fires"}

The case of the area named Agro Caleno, located in Campania (Italy) and belonging to the territory recently named "The Land of Fires" due to the fires that are lit around the area's mounds of waste, suggests some considerations. A succession of environmental and health crises has afflicted this area, creating serious difficulties for the structural stability of many businesses that produce protected designation of origin (PDO) food items, as well as the entire community.

After the waste emergency, the dioxin crisis of 2008-2009, and the new environmental crisis, it was immediately clear to businesses in the territory that it would be extremely difficult, if not impossible, for a single actor to manage these difficulties. Rather, solutions must be found within the supply chain (i.e., the network), particularly by involving local institutions. The research developed demonstrates the strong strategic importance of the decision to create a network addressing the consequences of environmental problems faced by businesses in Agro Caleno (De Chiara, 2015). The network, devised by a group of buffalo and agricultural businesses, has promoted the creation of a plan of conservation and development of the regional landscape of the Agro Caleno area, which has gained the approval of many municipalities in the area. In 2011, the plan was turned into the document Memorandum of Understanding, (Protocollo d'intesa per la valorizzazione dell'Agro Caleno-basso Volturno-sud Garigliano e del Water-front della provincia di Caserta), primarily aimed at the economic growth of the area, together with social progress and enhancement of cultural heritage.

However, while it was found that there is a considerable level of cooperation, the network has not produced the estimated results, and the Memorandum was not followed by a concrete process of action implementation to achieve agreed-upon objectives.

The research collected different considerations of the stakeholders involved. Local companies believe it is important to strengthen the action of the network to which they belong through meetings with district municipalities and to reaffirm the desire and need to give life to a 
redevelopment project that is supported by technical and local administrations. Local municipalities consider provincial and regional policies to be sophisticated procedures; local institutions were found to believe that the shortage of funds means that neither the transparency, nor the feasibility of the territorial reorganization is guaranteed. In addition, the research found a lack of effective coordination between the different initiatives and interviewees declared that national and regional plans constitute only positive intentions and assumptions of measures.

Thoughts of the local community are contained in an interview with Roberto Saviano, a famous Italian writer who has often addressed the issue of environmental pollution in Campania, published by La Repubblica (20 March 2014). He has described the work of the Inter-Ministerial Commission (which was demonstrated in the report entitled Results of Technical Research for the Mapping of the Territories Allocated to the Agriculture of the Campania Region) as unsatisfactory, using the word "minimizing" to describe the operations undertaken by the government, stating that "it is clear that the step taken in these first few months of work is only a small initial one to understand what has happened and continues to happen” (Saviano, 2014).

It seems clear that different actions have been carried out by the various parties acting independently. Lack of coordination and joint planning has resulted in an unsolved problem. Research results corroborate the hypothesis that in the face of complex problems (e.g., environmental pollution) and consequent crises faced by businesses that use the land as a productive factor, it is not sufficient to develop sustainable initiatives and collaborate with economic actors, industrial associations, and the local authorities. Resolving these crises requires more than cross-sector public and private partnerships; rather, it is necessary to initiate a systematic approach focused on the relationships between different stakeholders and progression towards shared goals. In this context, the collective impact approach could be applied to determinate the participation of economic, social, or political actors with the establishment of a backbone structure. Furthermore, by applying this approach, it should be possible to create a dedicated structure that could guarantee the participation of different actors. Moreover, it would enable the activation of a shared decision-making process, marked by precise phases, which could generate coordinated initiatives in the interest of all the parties.

As noted in the survey, companies have combined to form the Confagricoltura Campania, an entity representing all professional agricultural organizations in Campania. This entity could be the link between economic operators and institutions and, according to collective impact approach, could be an influential champion, able to resume a fruitful dialogue with local municipalities and define a more structured project to raise awareness on issues related to land and the environment involving local governments. Furthermore, it is believed that a clear definition of the different steps for this approach's implementation could assist its development by local institutions.

\section{The Tannery District of Solofra}

The tannery district of Solofra has represented one of the most interesting industries in southern Italy for a long time. The origins of tanning activities in Campania date back to the 16th century, when the production system had its own structure and possessed 51 tanneries overall. Today, in 
this area, there are about 600 operating businesses, 500 of which are mostly micro or small-sized enterprises (0-50 employees), while less than 100 are medium enterprises (51-250 employees).

Legal recognition of the Solofra tannery district was granted by the regional resolution No.70 on June 2, 1996 but research has shown that a path towards the creation and recognition of the district has not been conclusive (De Chiara, 2016). In actuality, the full operation of the district and a strategic implementation of its committees has never officially been approved; thus, all initiatives conducted by the district and for its development are transferred to public institutions or rely on the commitment of single entrepreneurs who strive to pursue viable actions.

In the area of sustainable development, research, consistent with thematic areas as indicated by ISO 26000 guidelines, highlights the major fields of concern on environmental issues and the community's engagement and development. This particular attention to the environment may be the result of the district's inner nature, namely its core businesses, whose impact has been reinforced by the presence of small businesses in the chemical industry and growing public concern about sustainability issues.

The district's most significant environmentally sustainable project is titled "An eco-label scheme for the district of Solofra.” The project earned the Homogeneous Production Area certification, issued by EMAS, making its objectives prominent in southern Italy (The Tannery district website).

The project's major objectives are to:

- $\quad$ create the best environmental conditions for the leather district

- achieve the Homogeneous Production Area (HPA) as a first step towards the EMAS certification for the entire district of Solofra

- re-launch the image of the district, allowing the operating businesses to improve international competitiveness through marketing actions focused on reducing the impact of their business practices on the environment.

The project, funded to point 4.3 Campania's regional operational program 2000-2006, sets as its primary objectives the creation and promotion of an eco-label for the tannery district of Solofra based on a method consistent with Regulation (EC) no.761/2001 governing the voluntary uptake of single organizations to the Community’s Eco-Management and Audit Scheme (EMAS).

The project engaged several stakeholders in Campania who collaborated to create a Committee composed of the Chamber of Commerce of Avellino, the Campania Region, the Province of Avellino, ARPAC, and other trade associations, such as ASI Consortium of Avellino, and select labor organizations of Avellino including CGL, CISL, and UIL, and the handmade organization of Avellino, CNA, as well as technical and scientific bodies (universities, CNR, the Institute for Experimental Leathers), the River Sarno body, and the district municipalities.

The leading committee has been entrusted with multiple tasks, including the definition and implementation of the district environmental policy, the orientation of the environmental management system, research into funding sources, the selection of partners for carrying out the 
program in all its stages, the drafting of rules for the voluntary labeling method, and the designing of the eco-label logo for the district of Solofra.

At present, 25 companies have the eco-label, but the project stopped due to lack of funds, and research justifies businesses' reluctance in exploiting the eco-label model due to poor market gains. Ideally, the adoption of the eco-label should have made businesses eligible for tax incentives or additional scores for tenders, but this has never been the case, not even in the notice of internal competitions issued by the Chamber of Commerce, thus explaining the lack of business interest in eco-label programs.

The absence of a unified and legitimate representation of a district governance has clearly influenced the possibility for businesses to create long-term policies and project planning development. Despite this absence, the environmental project has triggered a virtuous circle on a territorial level that managed to bring the local community closely in-line with district practices. In particular, the research singled out a few initiatives implemented by the district to benefit the community in which it operates. First, the eco-labeling initiatives may be interpreted as territorial marketing actions. A dedicated website for the district allows enhanced eco-label visibility to attract a broader number of businesses operating in the territory that can keep up to date with the project developments, namely new eco-labeled certified businesses, as well as performance results, news, conferences, and events. Furthermore, an interactive CD-ROM explaining eligibility for eco label certification and an informative leaflet indicating eco label advantages has been produced and is available. Both the CD-ROM and leaflets have been made available during the events organized by the Chamber of Commerce and/or Trade Associations.

Sustainability initiative management within the tannery industrial district of Solofra cannot rely on a decision-maker institution, as the district lacks a well-defined governance. The survey clearly shows that the district entrusts occasional committees with the task of developing and implementing sporadic projects, but the presence of a large number of firms in the district and the relevance of its production activities on the local community requires the definition of a small group of stakeholders who can decide on development strategies for the district and local systems. This group must be representative of various economic, political, and social sectors, but also, within the supply chain, of the different economic and structural characteristics of businesses, compared to the activities of the chain over which they are presiding.

Research suggests that the collective impact approach could be useful in defining a backbone structure and all subsequent aspects concerning the engagement of relevant members. This structure is essential to pursuing a sustainable development of district and of the local community. The business cluster examined is a typical Made in Italy district; it clearly enjoys a competitive advantage on an international level due to its strong ties with the economic and cultural heritage of the territory. However, this recognized advantage should be further strengthened by drawing on the adoption of collaborative approaches and sustainable competitive models, which will enable both the district to upgrade its production activities while reducing the pressure of competitive low-cost policies from developing countries, and also to anticipate and meet the increasing needs of the ethical market. 
Industrial district development means social upgrading and, thus, public institutions need to play an active role in civil society to trigger a learning process (Rivoli \& Waddock, 2011) that will facilitate the adoption of sustainable behavioral patterns.

By applying the collective impact approach, institutions should become influential champions and contribute to strengthening clustering approaches based on solid governances. The setting of a specific structure, or a leadership room, should allow the active participation of major components, namely district representatives and various actors in charge of the different phases and processes in the tannery supply chain. This structure should define the rules of the decisionmaking process and serve as the backbone for the entire initiative while coordinating participating organizations.

Finally, for the situation described in this case, the identification of specific phases necessary for the implementation of the collective impact approach appears to be a useful path to address the work of local governments.

\section{Conclusions}

The cases evaluated witness a failure of the traditional network and reaffirm that even if there is willingness to solve an environmental problem and constitute public- private partnerships, actions are not sufficient and the implementation of the collective impact approach could have better results.

It can be surmised that the distinctive nature of this approach is not ascribable to single elements, as certain pre-conditions (influential champion and financial resources) and conditions (governance and infrastructure, strategic planning, community involvement, evaluation, and improvement) are, which would assure the success of public-private partnerships. In fact, many of these elements are widely debated within the research as an issue of districts' and networks' governance (Schmitz \& Nadvi, 1999; Nelson \& Pritchand, 2009; Hemmati, 2002; Gereffi \& Lee, 2016). Rather, within the definition of a process, articulated in pre-conditions, conditions, and phases of implementation, appears the distinctive element of this approach that can represent a guarantor function, so that choices can be taken and implemented in the interest of all.

Another important aspect of this approach, in order to produce consistent and effective results, is to stress that all stakeholders must be aware that they need to completely change their own behavior to create a solution to serious problems. The collective impact is a new collaboration format designed to put an end to isolated impact and short-term solutions' (Prange, Allen \& Reiter-Palmon, p. 86), but the question is: Are the principal actors ready for this change? Do local public institutions understand the importance of reexamining the issues? The questions are still open, perpetuated by the issue of training the key actors towards the alignment of their behavior with this approach.

Further research can be addressed to deepen this issue and propose suitable practices for problemsolving through public-private partnerships. 


\section{References}

Barile, S., Saviano, M., Polese, F., \& Di Nauta, P. (2013). Il rapporto impresa-territorio tra efficienza locale, efficacia di contesto e sostenibilità ambientale. Sinergie, 90, 25-49. doi: 10.7433/s90.2013.04.

Becattini, G. (2000). Dal distretto industriale allo sviluppo locale. Torino: Bollati Boringhieri.

Becattini, G., \& Sforzi, F. (2002). Lezioni sullo sviluppo locale. Torino: Rosenberg \&Sellier.

Bennett, R. (1999). Business associations: Their potential contribution to government policy and the growth of small and medium-sized enterprises. Environment and Planning C: Politics and Space, 17(5), 593-608. https://doi.org/10.1068/c170593

Calvano, L. (2008). Multinational corporations and local communities: A critical analysis of conflict. Journal of Business Ethics, 82(4), 729-805. https://doi.org/10.1007/s10551-007-9593-z

Caroli, M., \& Tantalo, C. (2011). (Eds), Le Reti d’Imprese come strumento privilegiato per la diffusione di una Sostenibilità di Sistema. Luiss Business School. Retrieved from http://www.reloaderitalia.it/wp-content/uploads/2013/01/rapporto_luiss_reti_imprese.pdf.

Carter, C.R., \& Jennings, M.M. (2002). Logistics social responsibility: An integrative framework. Journal of Business Logistics, 23(1), 145-180. https://doi.org/10.1002/j.21581592.2002.tb00020.x

Dallocchio, M., Perrini, F., Vurro, C., \& Russo, A. (2010). Creare valore nella supply chain: modelli di gestione a confronto. Milano:EGEA.

De Chiara, A. (2015). From stakeholder engagement to the collective-impact approach for sustainability paths in complex problems. Sinergie, 33(96), 75-91.

https://doi.org/10.1080/00343400050005844

De Chiara, A. (2016). Implementing sustainability strategies in networks and clusters principles, tools and new research outcomes. Berlin: Springer International Publishing.

Feser, E., \& Bergaman, E.M. (2000). National industry cluster templates: Framework for applied regional cluster analysis. Regional Studies, 34, 1-19. doi:10.1080/00343400050005844

Fichter, M, \& Sydow, J. (2002). Using networks towards global labor standards? Organizing social responsibility in global production chains. Industrielle Beziehungen, 9(4), 357-380.

Gereffi, G., \& Lee, J. (2016). Economic and social upgrading in global value chains and industrial clusters: why governance matters. Journal of Business Ethics, 133(1), 25-38. https://doi.org/10.1007/s10551-014-2373-7 
Hanleybrown, F., Kania, J., \& Kramer, M. (2012). Channeling change: Making collective impact work. Stanford Social Innovation Review. Retrieved from http://www.ssireview.org/blog/entry/channeling_change_making_collective_impact_work.

Harvey, B., Van Luijk, K., \& Corbetta, G. (Eds.) (1991). Market morality and company size. London: Kluver. https://doi.org/10.1007/978-94-011-3556-6

Hemmati, M. (2002). Multi-stakeholder Processes for Governance and Sustainability. London: Earthscan Publications Ltd.

Iannone, R. (2007). Lo specchio della rete. Dinamiche sociali ed economiche a confronto. In R . Benini. (Ed.), L'impresa responsabile e la comunità intraprendente (pp.23-50). Matelica (MC): Halley Editrice.

Kania, J., \& Kramer, M. (2011). Collective impact. Stanford Social Innovation Review, Winter. Retrieved from http://ssir.org/articles/entry/collective_impact.

Neilson, J., \& Pritchard, B. (2009). Value chain struggles: Institutions and governance in the plantation districts of South India. Malden, MA: Wiley. https://doi.org/10.1002/9781444308723

Orlitzky, M., Schmidt, F.L., \& Rynes S. L. (2003). Corporate social and financial performance: A meta-analysis. Organization Studies, 24(3), 403-441. https://doi.org/10.1177/0170840603024003910

Perrini, F., \& Tencati, A. (2008). Corporate social responsibility. Milano: Egea.

Perrini, F., Pogutz, S., \& Tencati, A. (2006). Developing corporate social responsibility. A european perspective. Cheltenham: Edward Elgar Publishing.

Pilotti, L., Apa, R., Tedeschi-Toschi, A., \& Sarman, I. (2013). La competitività dinamica degli ecosistemi territoriali. Il caso degli ecosistemi turistici multilocali tra Italia e Svizzera. Sinergie, 91, 83-102. doi:10.7433/s96.2015.05

Porter, M.E, \& Kramer, M.R. (2006). Strategy \&society: The link between competitive advantage and corporate social responsibility. Harvard Business Review, 84(12), 78-92.

Prange, K., Allen, J. A., \& Reiter-Palmon, R. (2016). Collective Impact versus Collaboration: Sides of the Same Coin OR Different Phenomenon?. Metropolitan Universities, 27(1), 86-96.

Reuter, C., Foerstl, K., Hartmann, E., \& Blome, C. (2010). Sustainable global supplier management - the role of dynamic capabilities in achieving competitive advantage. Journal of Supply Chain Management, 46 (2), 45-63. https://doi.org/10.1111/j.1745-493X.2010.03189.x

Rivoli, P., \& Waddock, S. (2011). First they ignore you...: The time context dynamic and corporate responsibility. California Management Review, 53(2), 87-104.

https://doi.org/10.1007/s10551-012-1519-8 
Saviano, R. (2014). Il dossier ministeriale sull'inquinamento dei terreni tra Napoli e Caserta suscita perplessità. E solo il punto di partenza. Ecco come andare avanti. La Repubblica, 20 marzo.

Schmitz, H., \& Nadvi, K. (1999). Clustering and industrialization: Introduction. World Development, 27(9), 1503-1514. https://doi.org/10.1016/S0305-750X(99)00072-8

Spence, L.J., \& Schmidpeter, R. (2003). SMEs, social capital and the common good. Journal of Business Ethics, 45(1-2), 93-108. https://doi.org/10.1023/A:1024176613469

Spence, L.J., Schmidpeter, R., \& Habisch, A. (2003). Assessing social capital: Small and medium size enterprises in Germany and U.K. Journal of Business Ethics, 47(1), 17-29. https://doi.org/10.1023/A:1026284727037

Tencati, A., \& Zsolnai, L. (2009). The Collaborative Enterprise. Journal of Business Ethics, 85(3), 367-376. https://doi.org/10.1007/s10551-008-9775-3

Zadek, S. (2006). The logic of collaborative governance: corporate responsibility, accountability, and social contract. Corporate Social Responsibility Initiative Working Paper No.17. Cambridge, MA: J.F Kennedy School of Government, Harvard University. 


\section{Author Information}

Alessandra De Chiara is an Associate Professor of Management and Business Administration, Ethics and Market at the University of Naples "L'Orientale," Italy. She obtained a master's degree and a Ph.D. in Business Administration at the University of Venice, Italy. Her scientific activity is mainly dedicated to the in-depth study of sustainable strategies, corporate social responsibility, internationalization processes of enterprises, knowledge management and social mechanism, and small and medium-sized enterprises.

Alessandra De Chiara, Ph.D.

Human and Social Sciences Department

Largo San Giovanni Maggiore, 30

Napoli, 80100, Italy

E-mail: adechiara@unior.it

Telephone: 390816909449 